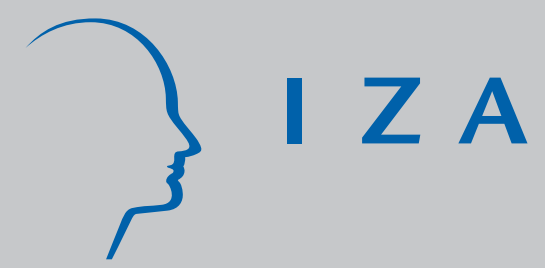

IZA DP No. 5721

Are Nurses More Altruistic than Real Estate Brokers?

Karin Jacobsen

Jo Thori Lind

Kari H. Eika

Karine Nyborg

Leif Helland

May 2011

Forschungsinstitut zur Zukunft der Arbeit Institute for the Study of Labor 


\title{
Are Nurses More Altruistic than Real Estate Brokers?
}

\author{
Karin Jacobsen \\ University of Oslo \\ Kari H. Eika \\ Royal Norwegian Ministry of Health and Care Services \\ Leif Helland \\ BI Norwegian School of Management \\ Jo Thori Lind \\ University of Oslo \\ Karine Nyborg \\ University of Oslo and IZA
}

Discussion Paper No. 5721
May 2011

IZA

P.O. Box 7240

53072 Bonn

Germany

Phone: +49-228-3894-0

Fax: +49-228-3894-180

E-mail: iza@iza.org

Any opinions expressed here are those of the author(s) and not those of IZA. Research published in this series may include views on policy, but the institute itself takes no institutional policy positions.

The Institute for the Study of Labor (IZA) in Bonn is a local and virtual international research center and a place of communication between science, politics and business. IZA is an independent nonprofit organization supported by Deutsche Post Foundation. The center is associated with the University of Bonn and offers a stimulating research environment through its international network, workshops and conferences, data service, project support, research visits and doctoral program. IZA engages in (i) original and internationally competitive research in all fields of labor economics, (ii) development of policy concepts, and (iii) dissemination of research results and concepts to the interested public.

IZA Discussion Papers often represent preliminary work and are circulated to encourage discussion. Citation of such a paper should account for its provisional character. A revised version may be available directly from the author. 
IZA Discussion Paper No. 5721

May 2011

\section{ABSTRACT}

\section{Are Nurses More Altruistic than Real Estate Brokers?*}

We report results from a dictator game experiment with nurse students and real estate broker students as dictators, and Amnesty International as the recipient. Although brokers contributed substantial amounts, nurses contributed significantly more, on average 76 percent of their endowment. In a second part, subjects chose between a certain repetition of the experiment and a 50-50 chance of costly exit. About one third of the brokers and half of the nurses chose the exit option. While generosity was indeed higher among nurses, even when taking exits into account, the difference cannot readily be attributed to different degrees of altruism.

JEL Classification: D10, D64

Keywords: dictator game, exit option, generosity, occupational differences

Corresponding author:

Karine Nyborg

Department of Economics

University of Oslo

P.O. Box 1095 Blindern

NO-0317 Oslo

Norway

E-mail: karine.nyborg@econ.uio.no

\footnotetext{
* Thanks to Equality, Social Organization, and Performance (ESOP) for funding, and to Kenneth Birkeli, Haakon Riekeles, Sunniva Eidsvoll Pettersen, Guro Synnes, Gyda Askestad and Marianne Tønnesen for excellent research assistance. Lind and Nyborg are part of Equality, Social Organization, and Performance (ESOP), which is funded by the Research Council of Norway.

The views expressed here are the authors' and do not reflect the views of the Royal Norwegian Ministry of Health and Care Services.
} 


\section{Introduction}

There seems to be a myth that people holding certain occupations, such as nurses, are generally more caring, generous or altruistic than others. As wonderfully represented by the Hollywood character Gordon Gekko in his famous statement greed is good, ${ }^{l}$ certain other occupations - such as financial market traders - seem, on the other hand, to be associated with egoism. In the present paper, we explore this myth by comparing the generosity of two student groups - nurse students and real estate broker students (henceforth, nurses and brokers) in an economic experiment. The main questions we address are the following: Are nurses more generous than brokers? If so, can this be attributed to a higher degree of altruism, the way this concept has been defined in the economics literature?

We approach these issues by means of a double-blind dictator game experiment in which a charity, Amnesty International, is the recipient. In Part 1 of our experiment, every subject was asked to share 100 Norwegian kroner (NOK), or about $16.5 \mathrm{USD}^{2}$, between themselves and Amnesty International. Our results show that brokers contribute, on average, a substantial 61 percent of their endowment; nurses' contributions were significantly larger, however, reaching an average of 75 percent. Thus, in this particular context, nurses were indeed more generous than brokers.

Part 2 of our experiment is inspired by the work of Dana, Cain and Dawes (2006); Dana, Weber and Kuang (2007); Lazear et al. (2006), and Broberg et al. (2007). These authors show that when subjects are given the option to exit a dictator game, or when the consequence for others of the dictator's choice is obscured, generosity is substantially reduced. In the second part of our experiment, therefore, subjects were given the choice between two options, A and B. Option A implied repeating the game from Part 1 with certainty. Option B implied a 50 percent probability of repeating the game from Part 1, and a 50 percent probability of receiving 90 NOK with no opportunity to donate to Amnesty International. Thus, option B implied a 50 percent probability of costly exit from the dictator game situation.

Nurses were substantially more likely to opt for the exit alternative than brokers: 36 percent of brokers and 51 percent of nurses chose B. Interestingly, however, those subjects who opted for exit but drew a repetition of the dictator game contributed substantial amounts: 31 percent for brokers and 42 percent for nurses. Even after accounting for exit behavior, nurses were more generous than brokers (in Part 2 and in total).

As we discuss in more detail below, this pattern of behavior is hard to reconcile with most standard models of social preferences. One possible explanation, however, could be that nurses experience a stronger sense of duty to conform with moral ideals (Brekke et al. 2003, Cappelen et al. 2007, Konow 2010, Nyborg 2011), and that this sense of duty applies more strongly to sharing decisions than to exit decisions.

\section{Occupational differences in generosity: theory and evidence}

Previous theoretical research within economics provides several reasons why one might expect occupational differences in generosity.

First, there is a recent strand of literature arguing that more cooperative individuals may self-select into certain jobs or professions, nursing being one much used example (Heyes 2005; Besley and

\footnotetext{
${ }^{1}$ From Oliver Stone's movie Wall Street (1987).

${ }^{2}$ Exchange rate per November 23, 2010.
} 
Ghatak 2005; Prendergast 2007; Delfgaauw and Dur 2008; Brekke and Nyborg 2008, 2010; Brekke et al. 2009). The argument is, in brief, that a combination of relatively low pay and intrinsically rewarding work is attractive only to those who are intrinsically motivated. Brekke and Nyborg (2010) distinguish between two production sectors, one in which workers are paid according to their marginal productivity and another, 'nursing', where efforts are not verifiable and wages are thus fixed. Brekke and Nyborg show that a preference to be important to others simply reinforces market incentives in the first sector, not changing effort choices at all, while a similar preference can have profound effects on effort in the nursing sector. They show, moreover, that if nurses' wages are kept sufficiently low, workers with strong preferences for being important to others will self-select into nursing, thus ensuring that nurses provide high effort levels even in the absence of monetary incentives to do so. Since the essential difference between the two sectors in their model is the different incentive structures, not the nature of the work, this provides one rationale for picking real estate agent students as the group being compared to nurses in our study: While fixed, relatively low wages seems to be the standard for nurses, real estate agents typically receive a substantial share of their pay through performance measures.

Occupational differences in generosity could, alternatively, be caused by socialization into occupationspecific norms and identities (Freidson 2001) rather than self-selection by highly motivated individuals. Akerlof and Kranton (2000) assume that there exists a plurality of social categories, as well as a prescription of appropriate or ideal behaviors for each group. Deviating from the prescription induces a utility loss via weakening the person's feeling of identity or 'sense of self'. If, for some reason, the social category nurse is associated with different prescriptions than broker, identity concerns could cause students identifying with each of these categories to behave differently even in a completely anonymous laboratory experiment. ${ }^{3}$

Although dictator game experiments have often been used to study generosity, dictator behavior can hardly yet be said to be well understood. Dictator giving is, for example, highly sensitive to the construction of choice sets (Dana et al. 2006; List 2007; Bardsley 2008, Asheim et al. 2010), whether endowments are earned (Cherry et al. 2002) and the degree of dictator anonymity (Hoffman et al. 2008). Such findings are hard to reconcile with standard economic models of preferences defined only over final outcomes. Thus, it is of interest to explore whether a higher generosity among nurses could be explained in the perhaps most straightforward way; that nurses, for whatever reason, simply have stronger preferences for others' welfare, or for giving per se, than brokers. This is the motivation for Part 2 of our experiment.

While a number of experiments have explored variations in ultimatum -and dictator game behavior over academic majors, results are mixed. Some studies find economic students to be less generous (Carter and Irons 1991; Cappelen, Nygaard, Sørensen and Tungodden 2010); others find the opposite (Kahneman et al. 1986; Frey and Bohnet 1995); while still others find no effects (Eckel and Grossman 1996; Kagel et al. 1996). No simple and robust gender differences seem to exist in dictator behavior (Bolton et al. 1998; Eckel and Grossman 1996, Croson and Gneezy 2009).

\footnotetext{
${ }^{3}$ Note that our experimental design cannot distinguish between the self-selection and socialization theories; both provide reasons, however, that looking for occupational differences in generosity may be worthwhile. Cappelen, Nygaard, Sørensen and Tungodden (2010) found substantial differences in generosity between the student population at the Norwegian School of Economics and Business Administration and the general population (with business /economics students being less generous), while Cappelen, Sørensen and Tungodden (2010) compared the behavior of first- and last-year students at the same school and did not observe substantial differences; these findings would speak for at least some self-selection effect.
} 
To our knowledge, no previous experiments have explored the dictator behavior of nurses. However, Cadsby and Maynes (1998) compared the behavior of business and economics students to nurses in a provision point public good game, and found nurses to be more cooperative: While cooperation among the business and economics students quickly collapsed, nurses started out with higher contributions, were willing to continue contributing even after rounds where the threshold was not reached, and generally tended to move around the cooperative equilibrium.

\section{Exit and motives for generosity}

Our interest lies not only with the level of generosity, but also its possible underlying causes. As indicated above, several aspects of dictator behavior seem inconsistent with standard economic models of selfishness or altruism where preferences are defined over material outcomes. For example, Dana et al. (2007) compared a binary choice baseline, in which a large majority of dictators preferred the "fair" allocation $(5,5)$ to the "unfair" alternative $(6,1)$, with alternative treatments enabling dictators to obscure the relationship between their actions and the resulting outcomes. In these alternative treatments, generosity was significantly lower than in the baseline case. ${ }^{4}$ This and similar experiments may indicate that subjects are motivated by a sense of moral obligation; that this sense is not independent of situational context; and that some subjects prefer to avoid contexts associated with a moral responsibility. ${ }^{5}$

Individuals may have a preference for keeping moral obligations and yet feel ambivalent towards this sense of obligation. Moral prescriptions and self-interest (narrowly defined) often conflict. In cases of unresolved internal conflicts, cognitive dissonance theory (Festinger 1957; see Aronson et al. 2005) predicts that the perceived trade-off between self-interest and moral obligation may be highly sensitive to apparently irrelevant modifications of experimental design.

As demonstrated by Bicchieri (2006), however, there is no universal consensus that giving in dictator games is morally superior to not giving. In a survey asking respondents to consider a standard dictator game, as many as 56 percent did not consider any allocation 'excessively greedy or unfair'. In the current experiment, our choice of a charity as the recipient aims specifically at increasing the probability that subjects consider giving a morally superior choice. Previous studies indicate that giving increases if the recipient is a charity (Eckel and Grossman 1996). ${ }^{6}$ To account for variations in subjects' attitudes to this particular charity, we used a post-experimental survey.

As Dana et al. (2006), Lazear et al. (2006), and Broberg et al. (2007) we introduce a costly exit (in Part 2 of the experiment). These studies all demonstrate that some dictators prefer to exit the dictator game even if exit reduces monetary pay-off. In Dana et al. (2006), subjects first made the sharing decision (as in a standard $\$ 10$ dictator game) and were subsequently given an option to exit (ex post exit option). About a third of participants chose exit, that is, accepted $\$ 9$ to keep, while the recipient would receive nothing and would not be told that a dictator game was to be played. Broberg et al. (2007) replicated the Dana et al. (2006) study, but instead of simply offering a fixed exit cost, they estimated participants' exit reservation prices. Almost two-thirds of their dictators had exit reservation values inconsistent with preferences defined over outcomes only. The study most similar to ours is that of Lazear et al. (2006). Here, dictators were first asked to divide $\$ 10$ between themselves and another participant, and the majority chose to share at least some of their endowment. In a second round, the

\footnotetext{
${ }^{4}$ See also Larson and Capra (2009).

${ }^{5}$ For discussions, see Nyborg (2011), Eika (2011).

${ }^{6}$ In Eckel and Grossman's study, Red Cross was the recipient. In our case we preferred to use a different charity since nurses may feel more strongly associated with the Red Cross than brokers.
} 
same subjects were given the choice between repeating the game and "pass", where the latter meant receiving \$10 without the opportunity to share. Most subjects - including many who had given the recipient a substantial share in the first round, thus apparently having preferences for sharing - chose to pass, avoiding the sharing option altogether. In subsequent rounds, the researchers introduced a strictly positive cost of opting out; still, a substantial share of subjects chose to pass.

For an individual who cares only about her own material consumption, choosing costly exit in a dictator game is strictly dominated by playing the dictator game and keeping everything. For a pure altruist (Andreoni 1988), costly exit is strictly dominated too: For someone who cares about her material payoff as well as the aggregate payoff to Amnesty International, playing the dictator game offers a larger set of feasible allocations other than exiting, including some that are strictly preferred to the payoffs implied by exit. Nor can Andreoni's (1990) impure altruism model, in which the individual has preferences for her own consumption, aggregate public good supply and her own contribution level, solve the puzzle: A dictator game offers the subject the option of higher payoff to herself, higher payoff to Amnesty International, and more own giving than costly exit.

As long as there are no restrictions on allowed dictator allocations, similar reasoning holds for inequity aversion models (Bolton and Ockenfels 2000; Fehr and Schmidt 1999). The non-strategic nature of the game precludes explanations based on reciprocity (Rabin 1993); and since our experiment is doubleblind, theories of social esteem, social approval etc. are of little relevance.

Dana et al. (2006) interpret the observed exit behavior in their experiments as reflecting a desire not to violate the recipient's expectations (Charness and Duwfenberg 2006, Battigalli and Dufwenberg 2007). If a dictator chose the exit option in Dana et al.'s experiment, her recipient would never get to know about the dictator game, thus there would be no expectations to violate. In an alternative treatment, however, Dana et al. (2006) did not tell recipients receiving money why they did so. In this latter case, hardly any dictators chose to exit. Dana et al. (2006) conclude, thus, that giving is motivated by a desire not to disappoint recipients' expectations. In our experiment, however, this explanation would seem considerably less plausible: Amnesty International is not a person, and neither individual members of the organization, its employees, nor its beneficiaries would have any reason to expect donations from our experiment. In a recent experiment by Ellingsen et al. (2010) a novel procedure is used to induce the dictator's second order beliefs; the dictator's beliefs about the recipient's beliefs about how much the dictator is going to give. These induced second order beliefs do not correlate with actual giving in the experiment, casting doubt on the explanatory power of guilt aversion even in experiments with human recipients present in the lab.

If a subject experiences a salient moral dilemma between contributing to Amnesty International and keeping money for herself, she can resolve the dilemma either by giving up a lot of money or by giving up her good conscience. She cannot have both. Exit removes, perhaps, the salience of the dilemma, possibly enabling her to have, in fact, both.

\section{The Experiment}

The experiments were carried out in April and September 2010. Seven rounds of experiments were conducted at three different schools; BI Norwegian School of Management, Akershus University College and Oslo University College. We recruited students from two bachelor programs in nursing (Akershus University College and Oslo University College) and from the bachelor program in real estate brokerage (BI Norwegian School of Management). 
In total 194 subjects participated in the study; 62 men and 132 women. The full composition of subjects by gender, field of study, and experiment type is given in Table 1. We thus have a substantial overrepresentation of females, which is not surprising given that females are typically vastly overrepresented among nurse students. Note, however, that we only have micro level data on gender for 169 of our subjects (59 men and 102 women). ${ }^{7}$

[Table 1 about here]

All subjects participated in one experiment consisting of two parts. ${ }^{8}$ We ran two treatments: The Uncertain exit treatment, a dictator game with uncertain exit option as explained above (five sessions), and the Certain exit treatment (two sessions). The only difference between the Uncertain and Certain exit treatments is that in the latter, choosing alternative B in Part 2 implied certain costly exit, i.e. a 100 percent probability of receiving 90 NOK and no opportunity to donate to Amnesty International.

The uncertainty in the first of these treatments was introduced partly in order to obscure the consequences for the recipient of exiting, since previous evidence indicates that this decreases subjects' generosity (Dana, Weber and Kuang 2007; Lazear et al. 2006). In addition, however, it provides a chance to observe behavior of subjects who prefer to exit, but who are nevertheless placed in a dictator situation. In the Uncertain exit treatment, however, one possible explanation for exit could simply be a desire for excitement; if this was the sole explanation exit behavior would disappear altogether in the absence of a random element in the exit option. We thus included the Certain exit treatment to check whether we would still get exits in this case.

Subjects were seated in a large room. Each subject drew a random number making it possible to link decisions in the two parts. One subject was drawn to serve as a monitor. The monitor overlooked the counting of donations, received $250 \mathrm{NOK}$ for the job, but did not otherwise participate in the experiment. Procedures were double-blind and based on the use of coins, envelopes, paper and pens (no computers). The allocation of coins between the subject and Amnesty International was done while the subject was hidden behind a large box. For details, see the instructions in Appendix B.

At the end of the session, subjects were asked to answer a simple questionnaire. A bank receipt confirming the total amount of money donated to Amnesty International, as well as a confirmation from the monitor, was published on one of the experimenters' homepage.

\section{Experimental findings}

\subsection{Do nurses contribute more?}

In Part 1, average contributions were 74,6 NOK for nurse students and 61,0 NOK for broker students. The difference of 13.64 NOK is statistically significant both using a t-test $(\mathrm{p}=.0088)$ and a nonparametric Mann-Whitney test ( $\mathrm{p}=.014)$.

The full distribution of contributions by field of study is shown in the upper row of Figure 1, where the upper panel shows the cumulative distribution function and the lower panel a histogram. The

\footnotetext{
${ }^{7}$ Because of anonymity concerns, we did not ask for subjects' gender if one gender was represented by less than four subjects in a session. This happened in one session with 33 nurse students, where only three men were present. However, we do know that for each subject in this session there is a probability $(33-3) / 33=0.91$ for the subject being female.

${ }^{8}$ In the instructions, the two parts were called "Experiment 1" and "Experiment 2".
} 
contributions of nurses stochastically dominate those of brokers (i.e. for any contribution level, there are more brokers than nurses contributing less than this), so this is not only a difference in means. More than $12 \%$ of brokers contributed 0 , while all nurses contributed strictly positive amounts. Almost half of the nursing students contributed everything, i.e. $100 \mathrm{NOK}$, whereas only $13 \%$ contributed less than 50. Hence we can conclude that contribution levels are higher among nursing students than among real estate students.

[Figure 1 about here]

[Figure 1: Distribution of contributions by profession. Notes: Nurses shown with light red bars and dashed lines, brokers with dark blue bars and solid lines. All data used. For Part 2, only data on nonexiting subjects used. Total contribution is defined as the sum of contributions in Parts 1 and 2, where those who exited in Part 2 are assumed to contribute 0.]

Contributions in Part 2 for those who did not exit the experiment are shown in the middle row of Figure 1. In this part, nurses contributed on average $61.06 \mathrm{NOK}$, while brokers contributed 42.41 NOK. The difference of 18.65 NOK is statistically significant both with the t-test $(p=.0069)$ and the Mann-Whitney test ( $\mathrm{p}=0037)$.

Finally, we can compare the sum of contributions in both parts of the experiment. We define those exiting in Part 2 as contributing zero. Then, nurses contribute on average 122.33 NOK, while brokers contribute 94.19 NOK. The difference of 28.14 NOK is also significant both using a t-test $(\mathrm{p}=.0052)$ and the Mann-Whitney test $(\mathrm{p}=.0050)$. The distribution of total contributions shown in Figure 2 reveals, again, that the contributions by nurses stochastically dominate those of brokers.

Thus, in this particular setting there seems to be some truth to the myth:; nurses are more generous than brokers.

\subsection{Exit behavior}

Let us now consider the decision to exit the experiment, focusing mainly on the Uncertain exit treatment. Among the real estate students, 36 percent (16 out of 44) chose the exit option B, whereas 51 percent (46 out of 91 ) of the nursing students chose B. The difference is only weakly different from zero using a t-test for proportions $(\mathrm{p}=.12)$, so although nurses are more likely to exit, the tendency is not very certain.

In line with the results of Dana et al. (2006), Lazear et al (2006) and Broberg (2007) a substantial share of our subjects opted for a costly exit option. While Dana et al. (2006) explain exit behavior by a desire not to violate the recipient's expectation, this can hardly explain our results. . Next, contributions in Part 1 may say something about subject types relevant for subsequent exit choice Those who later choose alternative A in Part 2, i.e. a repetition of the dictator game, contributed on average 74.58 NOK in Part 1, and those who later choose exit (alternative B), contributed 71.94 in Part 1 . This difference is not significant at any meaningful level of significance.

This raw comparison, however, hides a pattern that can be seen in Figure 2, where we show cumulative distribution functions for contributions in Part 1 broken down by field of study and exit choice. It is seen that among real estate students, contributions appear to be higher among those who choose B in Part 2 - the lottery with possible exit - whereas the opposite pattern appears among the nursing students. Indeed, Part 1 contributions are NOK 11.70 higher among exiting brokers than repeating brokers (NOK 70.62 versus 58.93 NOK) but NOK 12.15 lower among exiting nurses 
compared to repeating nurses (72.39 NOK versus $84.55 \mathrm{NOK}$ ). While this difference is not significantly different from zero among the brokers $(\mathrm{p}=.34)$, it clearly is among the nurses $(\mathrm{p}=.038)$.

[Figure 2 about here]

[Figure 2: Distribution of contribution in Part 1 by profession and subsequent choice.]

Broberg et al (2007) and Dana et al. (2006) found a (weak) positive correlation between contributions in the game and the tendency to exit. We find the same tendency among brokers, but the opposite holds for nurses.

These findings are confirmed in the more formal logit analyses reported in Table 2, where we regress the choice of exit on field of study and/or Part 1 contribution. Neither of the variables are significant without the interaction (Columns (1) and (2)), but when we condition the effect of contribution in Period 1 on nurses and brokers in Column (3), it becomes clear that high contributions increases the likelihood of choosing exit for brokers while reducing it for nurses. This is also confirmed by splitting the sample between brokers and nurses in Columns (4) and (5).

[Table 2 about here]

\subsection{Contributions after choice of exit}

As mentioned in Chapter 3, generosity may be motivated by a sense of moral obligation. One possible hypothesis is that sense of obligation depends on the situational context. In part two of our experiment, subjects are faced with two types of choices; how (or whether) to share, and whether to exit the dictator game. Both have implications for payoff outcomes, but the moral responsibility associated with the two types of choices may differ. Our data seems consistent with this interpretation.

Another interpretation would be that those who chose the exit option B did so because they wanted to keep 90 NOK and did not, for some reason, realize that this was an option in alternative A as well. However, this does not seem to be supported by the data: Only 2 out of 28 subjects who chose B, but drew a repeated dictator game, chose the "exit like" strategy of keeping NOK 90 for themselves and contributing NOK 10 to the recipient.

How do contributions in the second part of the experiment differ between those who wanted to repeat Part 1 and those who chose B in Part 2, but still drew a repetition in the lottery? The distributions of contributions for the two groups are shown in Figure 3. Contribution levels were much higher in the former group than the latter, 65.88 NOK versus 38.29. This difference (27.59 NOK) is clearly significantly different from zero $(\mathrm{p}=.0005)$. Nevertheless, it is noteworthy that even those who opted for exit did contribute substantial amounts if they did in fact draw a repeated dictator game.

[Figure 3 about here]

[Figure 3: Distribution of contribution in Part 2 by choice of alternative. Notes: Subjects who chose to repeat the game depicted with solid lines and dark green bars, those who chose possible exit (and drew a repetition) in dashed lines and light orange bars. Only data from the treatment with uncertain exit employed.]

In Figure 4, the difference in contribution between those who chose, respectively, A and B in Part 2 is decomposed by profession. Again we see that nurses contribute more than brokers, but the difference between those choosing $\mathrm{A}$ and $\mathrm{B}$ is about the same, close to $12 \mathrm{NOK}$, among students of both professions. 
[Figure 4 about here]

[Figure 4: Distribution of contributions in Part 2 by choice of alternative and profession. Notes: Only data from the uncertain exit treatment used.]

\subsection{Certain exit}

Finally, it is interesting to see whether some subjects choose the exit option B even when this is not uncertain. Since alternative B was in practice a lottery, while alternative A was not, exit behavior may be motivated by a desire for excitement. If this was the only reason, however, we would hardly see exit when removing the lottery aspect.

In the Uncertain exit treatment, $46 \%$ of subjects (62 out of 135) chose alternative B in Part 2 (the lottery). In the Certain exit treatment, where alternative B in Part 2 implied getting for sure 90 NOK and no donation choice, only $28 \%$ (17 out of 60 ) chose alternative B. This difference is statistically significant ( $p=0.021$ ). The difference is mostly driven buy the nursing students where the difference is 21 percentage points $(\mathrm{p}=.05)$, whereas the difference is only $10 \%(\mathrm{p}=.38)$ among the real estate students.

Thus, while exit is preferred by fewer in the Certain exit treatment, a substantial share still choose alternative B. Exit behavior hence cannot be explained only on the basis of a desire for excitement. Note that one cannot readily conclude that the difference in exit behavior between the two treatments is indeed caused by a desire for excitement: In accordance with previous experiments, we would also expect that more subjects choose B in the Uncertain exit treatments due to the fact that the uncertainty obscures the consequences for others of one's choice.

\subsection{Profession or gender?}

We saw in Table 1 that there are clear gender biases in the choice of field of study. Indeed, 84 percent of the nurse students and only 38 percent of the broker students were female. Hence, the effects of profession seen above could be driven by gender differences in behavior.

[Table 3 about here]

Table 4 reports results from regressing contributions on profession and gender. In Column (1) it seems as if gender is more important than profession; the nurse dummy is still positive but not significant. This is hiding an interesting pattern revealed by the specification in Column (2), though. Here we also include the interaction between profession and gender. It turns out that nurses contribute more than brokers, and women more than men, but the effects do not accumulate. In fact, female and male nurses contribute, respectively, 76.99 and 71.43 NOK, i.e. about the same level of magnitude, while female and male brokers contribute 75.71 and 51.56 NOK, a major difference. Hence, it seems that the difference is mostly between male brokers and the other subjects. Columns (3) and (4) that reports results on contributions in Part 2 of the experiment show fairly similar patterns. From this we conclude that gender certainly plays a major role in shaping contribution levels, but profession is also important.

\subsection{Attitudes toward the charity}

A final worry may be that nurses and brokers, and men and women, have different attitudes toward the particular charity serving as our recipient, Amnesty International. This could in principle be the single driving force behind the findings described above. To check this, we included three questions on subjects' attitudes to Amnesty in the post-experimental questionnaire. Specifically, we asked subjects 
to rank from 1 to 5 their knowledge of the organization, their trust in the organization, and their judgment of the importance of the work of the organization. The answers to the three questions were heavily correlated, and a factor analysis revealed a single dominant factor. To simplify the analysis, we therefore decided to focus on the average response to the three questions. ${ }^{9}$

Estimations including these measures of attitudes are reported in Appendix A. First, Table A-1 shows that nurses and women tend to have higher esteem for Amnesty International than do men and brokers. The relationship is not very strong, though. In Table A-2 we include the attitude index in some of the baseline estimations shown above. We clearly see that subjects who report a higher esteem for the organization tend to have higher contributions both in Part 1 and 2 of the experiment. In any case, as the attitude index is not very heavily correlated with profession and gender, the results discussed above are qualitatively unchanged. Note, however, that if subjects feel a need to rationalize their own choices, reported attitudes to the charity may not be completely exogenous to contribution and/or exit behavior.

\section{Discussion}

As discussed above, exit behaviour is hard to explain using standard economic models. Several statements made in the post-experimental questionnaire, however, indicate that one motive for choosing exit is that it provides an option of monetary payoff to oneself without bad conscience. This would be in line with models assuming that people strive towards ideals of moral behaviour (Konow 2010, Nyborg 2011), but only if, for some reason, subjects feel more morally obligated to share when in the dictator game than to avoid the dictator game.

Consider, for example, the following responses to the question "why did you make the choices you did" from subjects in the Uncertain exit treatment who all chose B in Part 2, but drew a repeated dictator game:

I like surprises, and got the chance to 'win' money without bad conscience. (Broker; contributed 10 in Part 1 and 10 in Part 2).

Envelope B gave me an opportunity to win without getting a bad conscience. (Broker, contributed 70 in Part 1 and 50 in Part 2).

If I had received 90 NOK without any choice whether to donate it, I could have kept it with a good conscience, while when I had the option, I would give most of it to Amnesty. (Nurse, 80 NOK in Part 1, 80NOK in Part 2.)

Excitement. A wish to keep more money than I had the conscience to if I had chosen A. (Nurse, 70 NOK in Part 1, 40 NOK in Part 2.)

Such statements may seem puzzling; these subjects appear to act upon a feeling of responsibility when placed in the dictator position, while they do not appear to experience the same sense of responsibility for not exiting - although the exit decision certainly has implications for sharing too. Our results, like the results of other researchers cited above, thus seem to indicate that many individuals are willing to share when placed in 'sharing context', while at the same time preferring to avoid that context.

\footnotetext{
${ }^{9}$ This average is almost exactly proportional to the first principal component and yields results that are easier to interpret than what comes out of factor analyses and principal component analyses.
} 
For someone choosing the exit option, escaping from the moral dilemma must be worth at least 10 NOK. Note, however, that escaping the dilemma gives different observable consequences depending on how the subject would otherwise have resolved it, and on how large contributions she would otherwise need to make to avoid her own conscience - which may differ substantially between persons. Even if two persons with identical contributions in Part 1 both exit to get money with a clear conscience, the implication for the first might primarily be a better conscience, while for the second it may be more money. Similarly, there is not necessarily any clear relationship between the amount donated in Part 1 and the degree to which the subject experiences a bad conscience for not having given enough; that depends, of course, on what she thinks she should have done.

As reported above, it turns out that among nurses, those who exit are less generous than others; among brokers, the opposite holds. Still, however, in Part 1 exiting nurses contribute, on average, more than exiting brokers.

Nurses thus seem to be troubled more by their conscience than brokers for the same contribution level. One interpretation is that nurses are more duty-oriented than brokers, in the sense that they 1) experience stronger feelings of duty in the sharing context; 2) that this typically leads them to contribute high amounts when in the role of a dictator, and 3) if they do not, the associated bad conscience is strong. This would imply i) high contributions in part 1, ii) high exit in part 2, iii) high contributions from exiters who receive a second dictator game.

\section{Conclusions}

Using a dictator game with a costly exit option and with Amnesty International as the recipient, we find that nurse students are more generous when placed in the role as dictators than real estate broker students. However, this finding cannot simply be explained by nurse students being more altruistic in the sense that they care more about Amnesty International, or in the sense that they care more about their own giving. If that was the explanation, we should not observe high exit rates among the nurse students. While about one third of the brokers chose the exit option, more than half of the nurse students did. However, when choosing an uncertain exit option but drawing another dictator game, not the exit, nurse students contributed substantial amounts, leaving them with much less money than what their payoff would have been with the costly exit. This is consistent with the idea that at least part of the observed generosity is caused by a sense of duty which is context-specific in the following sense: The obligation to contribute when placed in a sharing context, is stronger than the obligation to place oneself in a sharing context. That nurses are more generous in the role as dictators, but also more prone to opt for exit, might thus be explained by nurses experiencing a stronger sense of duty than brokers, and that this sense of duty does not apply equally strongly to the exit choice as to the sharing choice.

If nurses are genuinely more altruistic towards others, the pleasure of helping would be a reward in itself, presumably stimulating generosity in predictable and stable ways. If nurses' high generosity is, instead, motivated by context-dependent moral obligation, this might be different. Depending on the specific relationships between context and responsibility, obligations might be avoided, for example, by choosing another occupation; by turning ones back to the needy; by reconsidering one's belief about the strictness of identity requirements for one's profession; or by otherwise redefining the situation as a less demanding one. Generosity caused by context-dependent moral obligation may thus possibly be more easily undermined, and more sensitive to seemingly unimportant contextual changes, than generosity driven by genuine altruism. 


\section{References}

Asheim, G.B., Helland, L., Hovi, J. and Høyland, B. (2010): Self-serving dictators, Memorandum 26/2008, Department of Economics, University of Oslo.

Akerlof, G. A., and Kranton, R. E. (2000): Economics and Identity, Quarterly Journal of Economics, 115(3), 715-753.

Andreoni, J. (1988): Privately Provided Public Goods in a Large Economy: The Limits of Altruism, Journal of Public Economics 35(1), 57-73.

Andreoni, J. (1990): Impure Altruism and Donations to Public Goods: A Theory of Warm-Glow Giving, Economic Journal, 100(401), 464-477.

Aronson, E., Wilson, T. D., and Akert, R. M. (2005). Social psychology. Upper Saddle River, N.J.: Pearson/Prentice Hall.

Bardsley, N. (2008): Dictator game giving: altruism or artefact? Experimental Economics, 11(2), 122133.

Battigalli, P., and M. Dufwenberg (2007): Guilt in Games, American Economic Review, Papers and Proceedings (97), 170-176.

Besley, T., and M. Ghatak (2005): Competition and Incentives with Motivated Agents, American Economic Review 95 (3), 616-636.

Bicchieri, C. (2006): The Grammar of Society. The Nature and Dynamics of Social Norms, New York: Cambridge University Press.

Bolton, G.E., Katok, E. and Zwick, R. (1998): Dictator game giving: Rules of fairness versus acts of kindness. International Journal of Game Theory, 27, 269-299.

Bolton, G.E. and Ockenfels, A. (2000): ERC: A theory of equity, reciprocity, and competition. American Economic Review, 90, 166-193

Brekke, K.A., K.E. Hauge, J.T. Lind and K. Nyborg (2009): Playing with the Good Guys: A Public Good Game with Endogenous Group Formation, Memorandum 8/2009, Department of Economics, University of Oslo.

Brekke, K. A., S. Kverndokk, and K. Nyborg (2003): An Economic Model of Moral Motivation, Journal of Public Economics 87 (9-10), 1967-1983.

Brekke, K.A. and K. Nyborg (2008): Attracting responsible employees: Green production as labor market screening, Resource and Energy Economics 30, 509-526.

Brekke, K. A. and Nyborg, K. (2010): Selfish bakers, caring nurses? A model of work motivation, Journal of Economic Behavior and Organization, 75(3), 377-394.

Broberg, T., Ellingsen, T. and Johannesson, M. (2007): Is generosity involuntary? Economics Letters, 94(1), 32-37. 
Cadsby, C. B. and Maynes, E. (1998). Choosing between a socially efficient and free-riding equilibrium: Nurses versus economics and business students. Journal of Economic Behavior and Organization, 37(2), 183-192.

Cappelen, A.W., Drange Hole, A., E.Ø. Sørensen and B. Tungodden (2007): The Pluralism of Fairness Ideals: An Experimental Approach. American Economic Review, 97(3):818-827.

Cappelen, A.W., K. Nygaard, E.Ø. Sørensen and B. Tungodden (2010): Efficiency, equality and reciprocity in social preferences: A comparison of students and a representative population, $\mathrm{NHH}$ Discussion Paper SAM28-2010, Bergen: Norwegian School of Economics and Business Administration.

Cappelen, A.W., E.Ø. Sørensen and B. Tungodden (2010): Responsibility for what? Fairness and individual responsibility, European Economic Review 54, 429-441.

Carter, J.R. and Irons, D. (1991): Are economists different and if so, why? Journal of Economic Perspectives, 5, 171-177.

Charness, G. and M. Dufwenberg (2006): Promises and Partnerships. SSRN paper, $19^{\text {th }}$ of May. http://papers.ssrn.com/sol3/papers.cfm?abstract_id=380083

Cherry, T.L., Frykblom, P. and Shogren, J.F. (2002): Hardnose the dictator. American Economic Review, 92(4), 1218-1221.

Croson, R. and U. Gneezy (2009): Gender Differences in Preferences, Journal of Economic Literature 47(2), 448-74.

Dana, J., Cain, D. M. and Dawes, R. M. (2006): What you don't know won't hurt me: Costly (but quiet) exit in dictator games, Organizational Behavior and Human Decision Processes 100(2), 193 201.

Dana, J., Weber, R. and Kuang, J. (2007): Exploiting moral wiggle room: experiments demonstrating an illusory preference for fairness, Economic Theory, 33(1), 67-80.

Delfgaauw, J. and Dur, R. (2008): Incentives and Workers' Motivation in the Public Sector, Economic Journal 118(525), 171-191.

Eckel, C. C. and Grossman, P. J. (1996): Altruism in Anonymous Dictator Games, Games and Economic Behavior, 16(2), 181-191.

Eika, K.H. (2011): Near and Generous: Gift Propensity and Chosen Emotional Distance. Memorandum 06/2011, Department of Economics, University of Oslo.

Ellingsen, T., Johannesson, M., Torsvik, G. and Tjøtta, S. (2010). Testing Guilt Aversion. Games and Economic Behavior 68, 95-107.

Fehr, E. and Schmidt, K. (1999): A theory of fairness, competition and cooperation. Quarterly Journal of Economics, 114(3), 817-868.

Festinger, L. (1957): Making a Difference, RAND Journal of Economics 38(3): 714-732

Freidson, E. (2001): Professionalism: The Third Logic, Chicago: University of Chicago Press. 
Frey, B. and Bohnet, I. (1995): Institutions affect fairness: Experimental investigations. Journal of Institutional and Theoretical Economics, 151(2): 286-303.

Heyes, A.G. (2005): The economics of vocation, Journal of Health Economics 24, 561-569.

Hoffman, E., McCabe, K. and Smith, V. (2008): Social Distance and Reciprocity in Dictator Games. In: C.R. Plott and V.L. Smith (eds.) Handbook of Experimental Economics Results. Volume 1. Amsterdam: North-Holland.

Kagel, J., Kim, C. and Moser, D. (1996): Fairness in ultimatum games with asymmetric information and asymmetric payoffs. Games and Economic Behavior, 13, 100-110.

Kahneman, D., Knetsch, J.L. and Thaler, R. (1986): Fairness as a constraint on profit seeking: Entitlements in the market. American Economic Review, 76, 728-741.

Konow, J. (2010): Mixed Feelings: Theories and Evidence on Giving, Journal of Public Economics 94, 279-297.

Larson, T., and Capra, C. M. (2009). Exploiting moral wiggle room: Illusory preference for fairness? A comment. Judgment and Decision Making, 4, 467-474.

Lazear, E., Malmendier, U. and Weber, R. (2006): Sorting in Experiments with Application to Social Preferences, National Bureau of Economic Research Working Paper Series No. 12041. Retrieved from http://www.nber.org/papers/w12041.

List, J. A. (2007): On the interpretation of giving in dictator games, Journal of Political Economy 115, $482-493$.

Nyborg, K. (2011): I Don't Want to Hear About it: Rational Ignorance Among Duty-Oriented Consumers, forthcoming, Journal of Economic Behavior and Organization.

Prendergast, C. (2007): The Motivation and Bias of Bureaucrats, American Economic Review 97(1), 180-196.

Rabin, M. (1993): Incorporating Fairness into Game Theory and Economics, American Economic Review 83, 1281-1302. 
Appendix A: Additional estimation results

[Tables A-1 and A-2 about here] 


\section{Appendix B: Instructions}

[Note: The instructions below are translated from Norwegian. Instructions are identical for both treatments except when mentioned explicitly.]

Welcome to the experiment. This is an economic experiment, in which you can earn money. This money is provided by a research institution. The results from the experiment will be used in a research project. It is therefore important that you follow certain rules. Mobile phones must be switched off and you are not allowed to talk during the experiment. Please raise your hand if you have questions. One of those responsible for the experiment will then come to you.

We will conduct two experiments, both with the opportunity to earn money. What you choose in Experiment 1 will not in any way affect your choices or your possible earnings in Experiment 2. All decisions will be anonymous. Neither the other participants nor those responsible for the experiment will be able to know which choices you make.

One of the participants has been drawn to serve as an observer. This person will witness the counting of money after the experiment, and confirm that this has been done correctly. The observer is paid NOK 250, and will need to stay for about 15 minutes longer than the other participants. The observer will not himself/herself participate in the experiment.

(Requests that the person who has drawn participant no. 1 raises a hand. This person will be the observer.)

\section{Experiment 1}

In a moment, you will receive a closed bubble envelope. When it is your turn, bring your envelope to the designated station. Stand behind the box so that you hide your choice.

Then open the envelope and take out the contents. The envelope contains two smaller envelopes, one unmarked and one marked "To Amnesty", ten ten-kroner (a total of NOK 100) and instructions. The instructions have the following text:

1. Write down your participant number on the inside of the bubble envelope.

2. Your task is to distribute the money between yourself and Amnesty International. The full amount of what you place in the envelope marked "To Amnesty" will be sent to Amnesty International. The amount you place in the small unmarked envelope is yours to keep. You are completely free to determine the distribution, but the entire sum of money should be distributed so that the amount in the two envelopes together totals NOK 100.

3. Seal both of the two small envelopes. The unmarked envelope is yours to keep, bring this home when the experiment is finished. Place the envelope marked "To Amnesty" back into the bubble envelope.

4. Put the unmarked bubble envelope in the box that is located between stations, marked "Submission".

5. Then return to your seat and wait for further instructions.

In order for you to know that the money is actually transferred to Amnesty International, we will post a receipt for payment on Karine Nyborg`s home page, http://folk.uio.no/karineny/. We will also post the observer`s confirmation.

We will now hand out the envelopes. Please do not open you envelope until it is your turn at one of the stations. 


\section{Experiment 2 [Certain exit treatment only]}

In a moment you will be handed two bubble envelopes, one marked A: I choose to repeat Experiment 1 and one marked B: I choose a payment of NOK 90 without any additional choices.

When it is your turn to go to one of the stations, bring both envelopes to the assigned station. You must then choose between envelope A and envelope B. Stand behind the box so that you hide your selection. Then open the envelope and follow the instructions. NOTE: YOU MUST OPEN ONLY ONE ENVELOPE!

It will still not be possible for others in the room to know your choices.

Envelope A has exactly the same content as the envelope you received in the previous experiment. If you choose this envelope, you will be asked to distribute NOK 100 between yourself and Amnesty International, and you are still completely free to choose the distribution.

Envelope B provides no further choices. This contains only one small envelope and NOK 90 which you can keep.

If you choose envelope A, the instructions will have the following text:

1. Write down your participant number on the inside of the bubble envelope.

2. Your task is to distribute the money between yourself and Amnesty International. The full amount of what you place in the envelope marked "To Amnesty" will be sent to Amnesty International. The amount you place in the small unmarked envelope is yours to keep. You are completely free to determine the distribution, but the entire sum of money should be distributed so that the amount in the two envelopes together totals NOK 100.

3. Seal the small envelopes. The unmarked envelope is yours to keep, you should take it with you when the experiment is finished. Place the envelope marked "To Amnesty" back into the bubble envelope.

4. Remember to remove both tags from the bubble envelopes.

5. Hand in both bubble envelopes. Put the opened envelope in the box marked "Submission", and the unopened envelope in the box "Unused envelopes". Both of these boxes will be located between the stations. The small unmarked envelope is for you to take home.

If you choose envelope $\mathbf{B}$, the instructions will have the following text:

1. Write down your participant number on the inside of the bubble envelope.

2. Place all the money (NOK 90) in the small unmarked envelope, which you will keep yourself.

3. Remember to remove the tag on both bubble envelopes.

4. Hand in both bubble envelopes. Put the opened envelope in the box marked "Submission", and the unopened envelope in the box "Unused envelopes". Both of these boxes will be located between the stations. The small unmarked envelope is for you to take home.

Once you have handed in both bubble envelopes you will be handed a simple questionnaire. This must be filled out, folded and left in the box by the exit. After the questionnaire is handed in, you are free to leave.

Thank you for your participation!

(Envelopes are handed out, then the experiment may begin) 


\section{Experiment 2 [uncertain exit treatment only]}

In a moment you will draw two bubble envelopes, one marked A: I choose to repeat Experiment 1 and one marked B: I choose the envelope with unknown content.

When it is your turn to go to one of the stations, bring both envelopes to the assigned station. You must then choose between envelope $\mathbf{A}$ and envelope B. Stand behind the box so that you hide your selection. Then open the envelope and follow the instructions. NOTE: YOU MUST OPEN ONLY ONE ENVELOPE!

It will still not be possible for others in the room to know your choices.

Envelope A has exactly same content as the envelope you received in the previous experiment. If you choose this envelope, you will be asked to distribute $100 \mathrm{kr}$ between yourself and Amnesty International, and you are still completely free to choose the distribution.

Half of the envelopes marked $\mathbf{B}$ contain exactly the same as envelope A. Therefore, if you have received one of these, and choose B, you will also in this case be asked to distribute NOK 100between yourself and Amnesty International.

The other half of the envelopes marked $\mathbf{B}$, however, provide no further choices. These contain only one small envelope and NOK 90 which you can keep.

Hence, if you choose envelope $\mathbf{B}$, you do not know what it contains, but both alternatives are equally probable.

If you choose envelope $\mathbf{A}$, or you choose envelope $\mathbf{B}$ and it contains the same as envelope $\mathbf{A}$, the instructions will have the following text:

1. Write down your participant number on the inside of the bubble envelope.

2. Your task is to distribute the money between yourself and Amnesty International. The full amount of what you place in the envelope marked "To Amnesty" will be sent to Amnesty International. The amount you place in the small unmarked envelope is yours to keep. You are completely free to determine the distribution, but the entire sum of money should be distributed so that the amount in the two envelopes together totals NOK 100.

3. Seal the small envelopes. The unmarked envelope is yours to keep, bring it with you when the experiment is finished. Place the envelope marked "To Amnesty" back in the bubble envelope.

4. Remember to remove both tags from the bubble envelopes.

5. Hand in both bubble envelopes. Put the opened envelope in the box marked "Submission", and the unopened envelope in the box "Unused envelopes". Both of these boxes will be located between the stations. The small unmarked envelope is for you to take home.

If you choose envelope B and you are not given further choices, the instructions will have the following text:

1. Write down your participant number on the inside of the bubble envelope.

2. Place all the money (NOK 90) in the small unmarked envelope, which you will keep yourself.

3. Remember to remove the tag on both bubble envelopes.

4. Hand in both bubble envelopes. Put the opened envelope in the box marked "Submission", and the unopened envelope in the box "Unused envelopes". Both of these boxes will be located between the stations. The small unmarked envelope is for you to take home. 
Once you have handed in both bubble envelopes you will be handed a simple questionnaire. This must be filled out, folded and left in the box by the exit. After the questionnaire is handed in, you are free to leave.

Thank for your participation!

You will now draw envelopes. Please wait to open the selected envelope until it is your turn at one of the stations.

(The participants draw envelopes, then the experiment may begin) 
Table 1: Subjects by gender, profession, and treatment type

\begin{tabular}{lcccccccc}
\hline & \multicolumn{3}{c}{ Men } & & \multicolumn{3}{c}{ Women } \\
\cline { 2 - 4 } & Certain exit & Uncertain exit & Total & & Certain exit & Uncertain exit & Total \\
\hline Broker & 21 & 24 & 45 & & 9 & & 19 & 28 \\
Nurse & 7 & $10(7)$ & $17(14)$ & & 23 & & $81(51)$ & $104(74)$ \\
\hline Total & 28 & $34(31)$ & $62(59)$ & & 32 & $100(70)$ & $132(102)$ \\
\hline
\end{tabular}

Notes: Gender data were not collected from one session due to anonymity concerns. Subject composition without these are given in parentheses.

Table 2: Exit choice in Part 2

\begin{tabular}{lccccc}
\hline & $(1)$ & $(2)$ & $(3)$ & $(4)$ & $(5)$ \\
\hline Nurse & 0.582 & & $2.415^{* * *}$ \\
& $(1.54)$ & & $(2.58)$ & & \\
Contribution in Part 1 & & -0.00245 & 0.00781 & 0.00781 & $-0.0165^{* *}$ \\
& & $(-0.47)$ & $(0.94)$ & $(0.94)$ & $(-2.03)$ \\
Nurse $\times$ Contribution & & & $-0.0243^{* *}$ & & \\
& & & $(-2.09)$ & & \\
$\mathrm{N}$ & 135 & 134 & 134 & 44 & 90 \\
Sample & All & All & All & Broker & Nurse \\
\hline
\end{tabular}

Notes: Coefficients are from a logit analysis with choice of (uncertain) exit in Part 2 as the dependent variable.

*, **, and *** denote significance at the 10, 5, and $1 \%$ level. 
Table 3: Occupation versus gender

\begin{tabular}{lcccc}
\hline & $(1)$ & $(2)$ & $(3)$ & $(4)$ \\
\hline Nurse & 6.049 & $18.97^{*}$ & $35.95^{*}$ & $39.37^{* *}$ \\
& $(1.10)$ & $(1.97)$ & $(1.94)$ & $(2.28)$ \\
Female & $16.24^{* * *}$ & $24.16^{* * *}$ & $22.70^{*}$ & $28.09^{* *}$ \\
& $(2.75)$ & $(3.17)$ & $(1.68)$ & $(2.22)$ \\
Nurse $\times$ female & & -19.43 & -26.84 & -31.69 \\
& & $(-1.63)$ & $(-1.22)$ & $(-1.54)$ \\
Chose exit & & & & $-30.91^{* * *}$ \\
& & & & $(-4.14)$ \\
Constant & $54.59^{* * * *}$ & $51.56^{* * *}$ & $31.05^{* * *}$ & $39.19^{* * *}$ \\
& $(12.53)$ & $(10.91)$ & $(3.39)$ & $(4.48)$ \\
\hline Part & 1 & 1 & 2 & 2 \\
$\mathrm{~N}$ & 193 & 193 & 107 & 107 \\
$\mathrm{R}^{2}$ & 0.0780 & 0.0907 & 0.0881 & 0.219 \\
\hline
\end{tabular}

Notes: Coefficients are from OLS regressions. Dependent variable is contribution in Part 1 (Columns (1) and (2)) and in Part 2 (Columns (3) and (4)).

Columns (3) and (4) are based on subjects facing a possibility of uncertain exit and either choosing or drawing repeated game. The subjects in the session where gender was not collected for anonymity reasons, the female dummy is assigned the fraction of women present (0.91). *, **, and *** denote significance at the 10, 5, and $1 \%$ level.

Table A-1: Determinants of attitudes

\begin{tabular}{lcccccc}
\hline & $(1)$ & $(2)$ & $(3)$ & $(4)$ & $(5)$ & $(6)$ \\
\hline Nurse & $0.258^{* *}$ & & 0.143 & 0.0864 & 0.191 & 0.136 \\
& $(2.37)$ & & $(1.14)$ & $(0.51)$ & $(1.13)$ & $(0.97)$ \\
Female & & $0.320^{* * *}$ & $0.242^{*}$ & $0.311^{*}$ & 0.0887 & $0.315^{* *}$ \\
& & $(2.76)$ & $(1.80)$ & $(1.70)$ & $(0.49)$ & $(2.10)$ \\
Constant & $3.616^{* * *}$ & $3.559^{* * *}$ & $3.524^{* * *}$ & $3.319^{* * *}$ & $3.158^{* * *}$ & $4.098^{* * *}$ \\
& $(42.33)$ & $(37.71)$ & $(35.45)$ & $(24.47)$ & $(23.54)$ & $(37.04)$ \\
\hline Dependent var & Index & Index & Index & Confidence & Knowledge & Objective \\
$\mathrm{N}$ & 192 & 192 & 192 & 192 & 193 & 192 \\
$\mathrm{R}^{2}$ & 0.0288 & 0.0386 & 0.0452 & 0.0278 & 0.0146 & 0.0505 \\
\hline
\end{tabular}

Notes: Coefficients are from OLS regressions. Dependent variables are measures of attitudes toward Amnesty International. *, **, and *** denote significance at the 10, 5, and $1 \%$ level. 
Table A-2: Contributions and attitudes

\begin{tabular}{lccc}
\hline & $(1)$ & $(2)$ & $(3)$ \\
\hline Nurse & 4.454 & $19.28^{* *}$ & $36.84^{* *}$ \\
& $(0.83)$ & $(2.05)$ & $(2.14)$ \\
Female & $13.66^{* *}$ & $22.68^{* * *}$ & $27.02^{* *}$ \\
& $(2.35)$ & $(3.05)$ & $(2.15)$ \\
Nurse $\times$ female & & $-22.41^{*}$ & -31.46 \\
& & $(-1.92)$ & $(-1.54)$ \\
Chose exit & & & $-31.46^{* * *}$ \\
& & & $(-4.24)$ \\
Attitude index & $10.19^{* * *}$ & $10.59^{* * *}$ & 8.766 \\
& $(3.27)$ & $(3.42)$ & $(1.63)$ \\
Constant & 18.72 & 13.81 & 7.806 \\
& $(1.59)$ & $(1.15)$ & $(0.37)$ \\
\hline Part & 1 & 1 & 2 \\
Treatment & Both & Both & Uncertain exit \\
N & 192 & 192 & 107 \\
$\mathrm{R}^{2}$ & 0.126 & 0.143 & 0.239 \\
\hline
\end{tabular}

Notes: Coefficients are from OLS regressions. Dependent variable is contribution. *, **, and ${ }^{* * *}$ denote significance at the 10, 5, and $1 \%$ level. 
Figure 1: Distribution of contributions by profession

Part 1

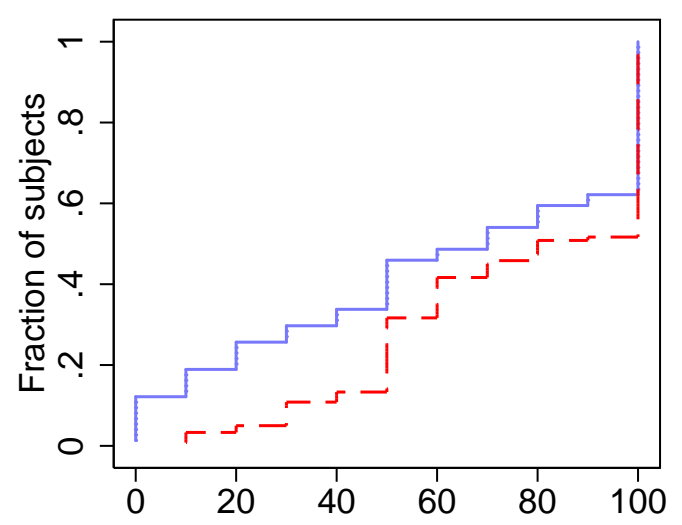

Part 2

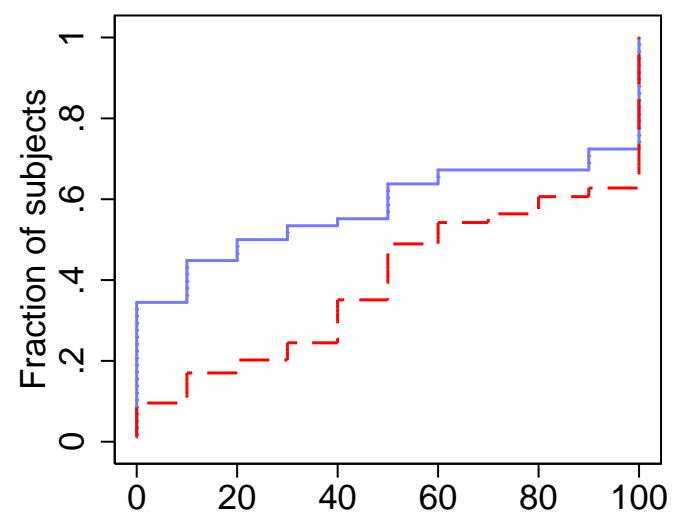

Both parts

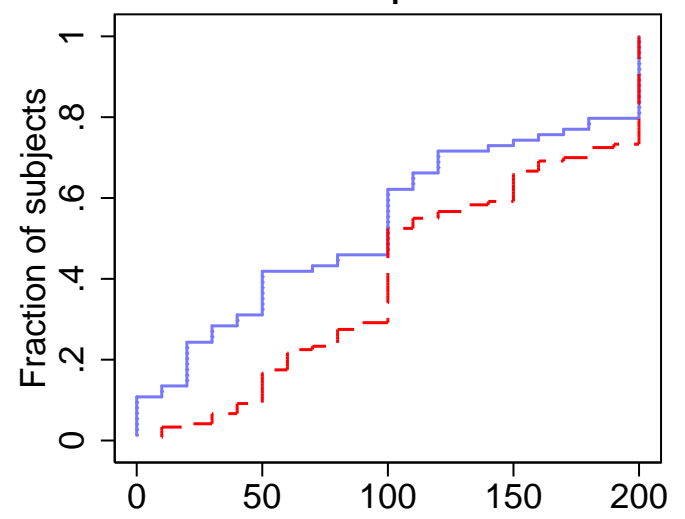

Part 1

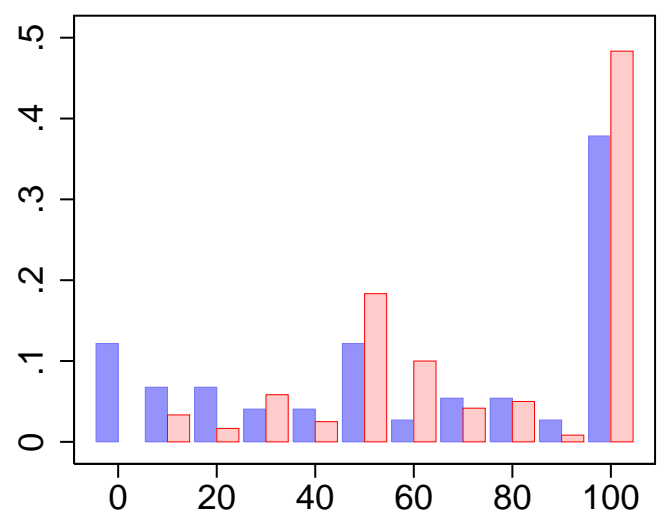

Part 2

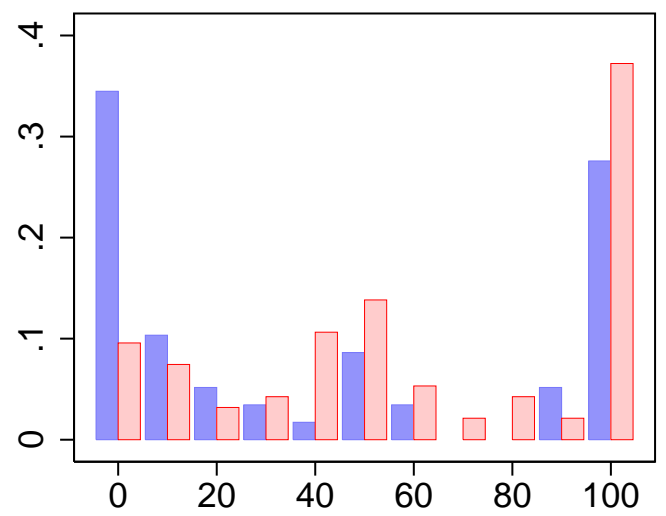

Both parts

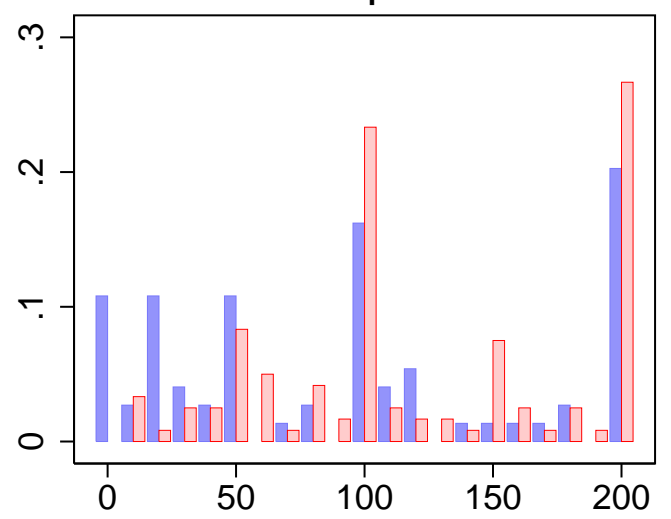

Notes: Nurses shown with light red bars and dashed lines, brokers with dark blue bars and solid lines.

All data used. For Part 2, only data on non-exiting subjects used. Total contribution is defined as the sum of contributions in parts 1 and 2 , where those who exited in part 2 are assumed to contribute 0. 
Figure 2: Distribution of contribution in Part 1 by profession and subsequent choice

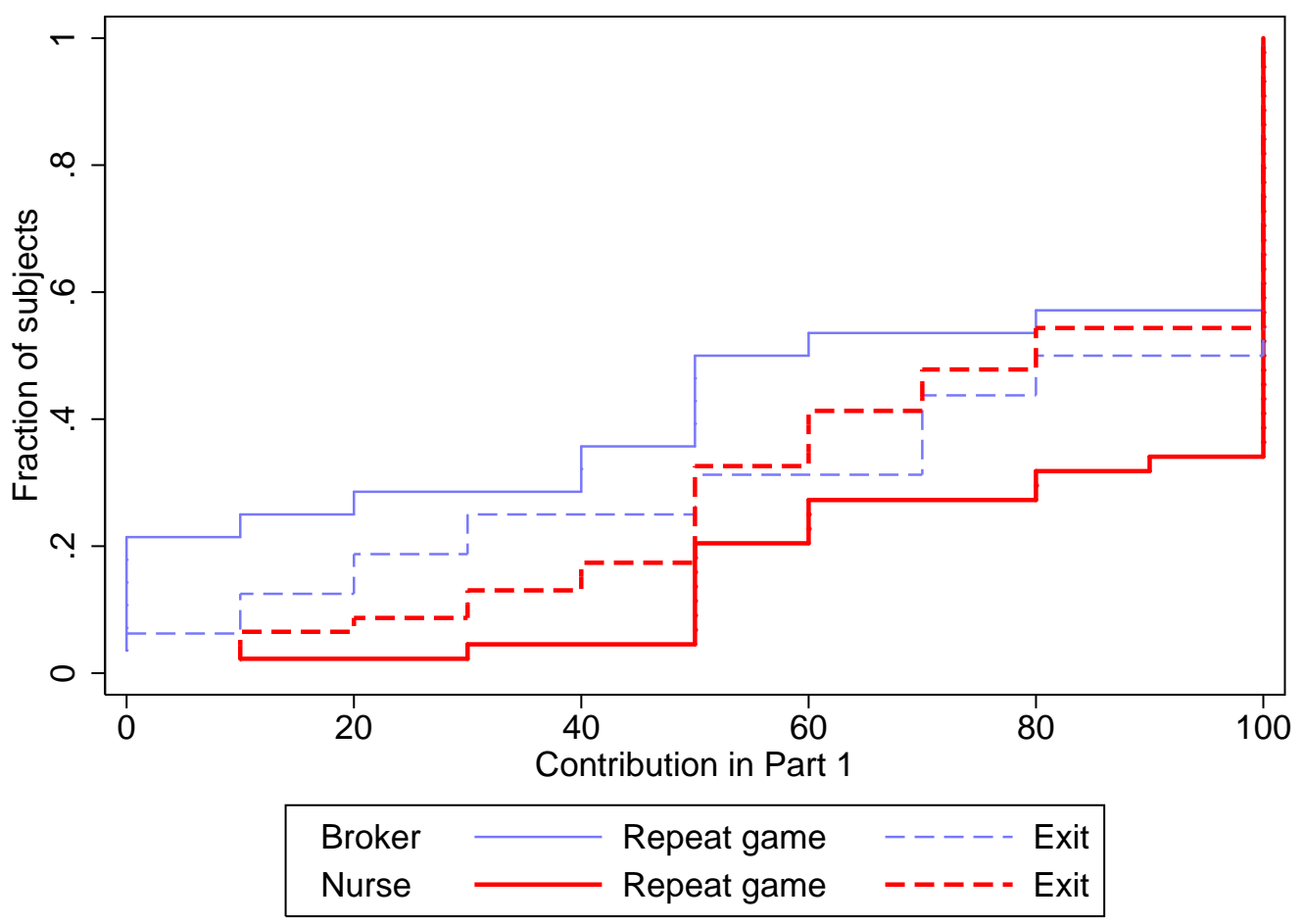

Figure 3: Distribution of contributions in Part 2 by choice of alternative
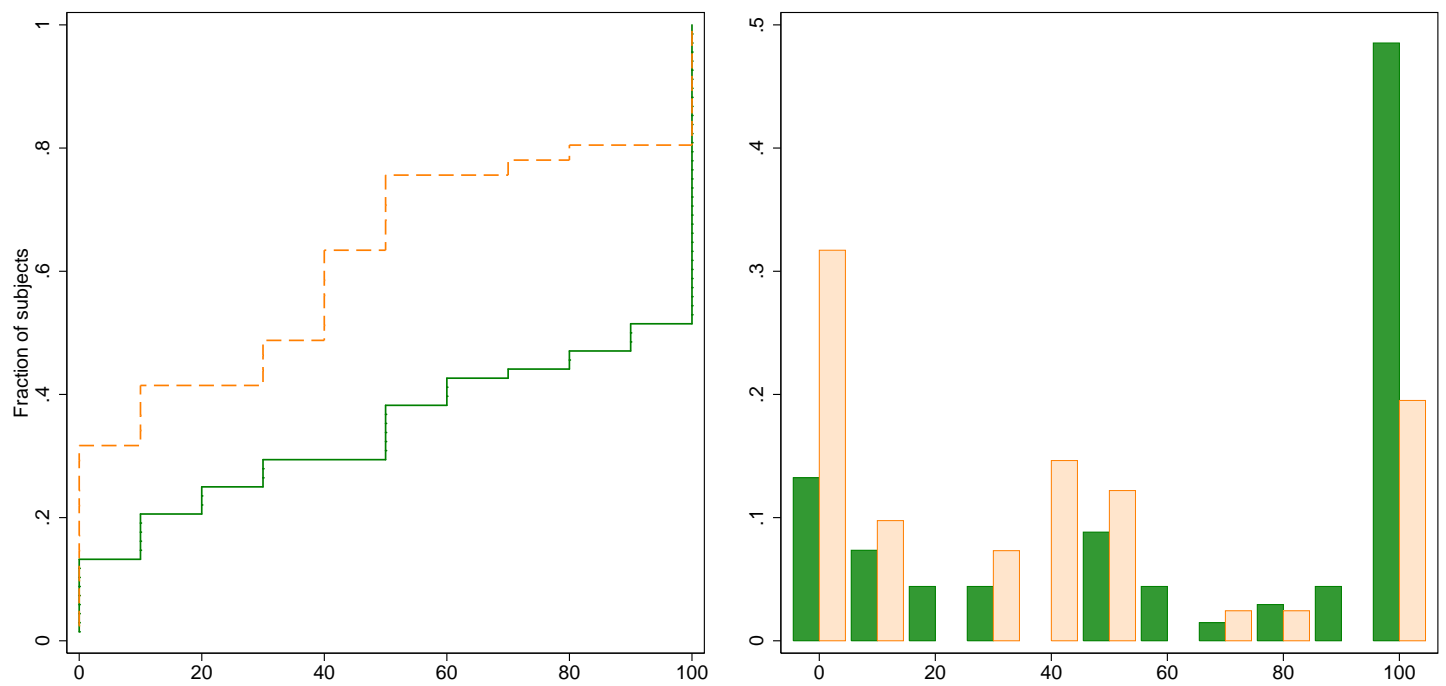

Notes: Subjects who chose to repeat the game depicted with solid lines and dark green bars, those who chose possible exit (and drew a repetition) in dashed lines and light orange bars. Only data from the treatment with uncertain exit employed. 
Figure 4: Distribution of contributions in Part 2 by choice of alternative and profession

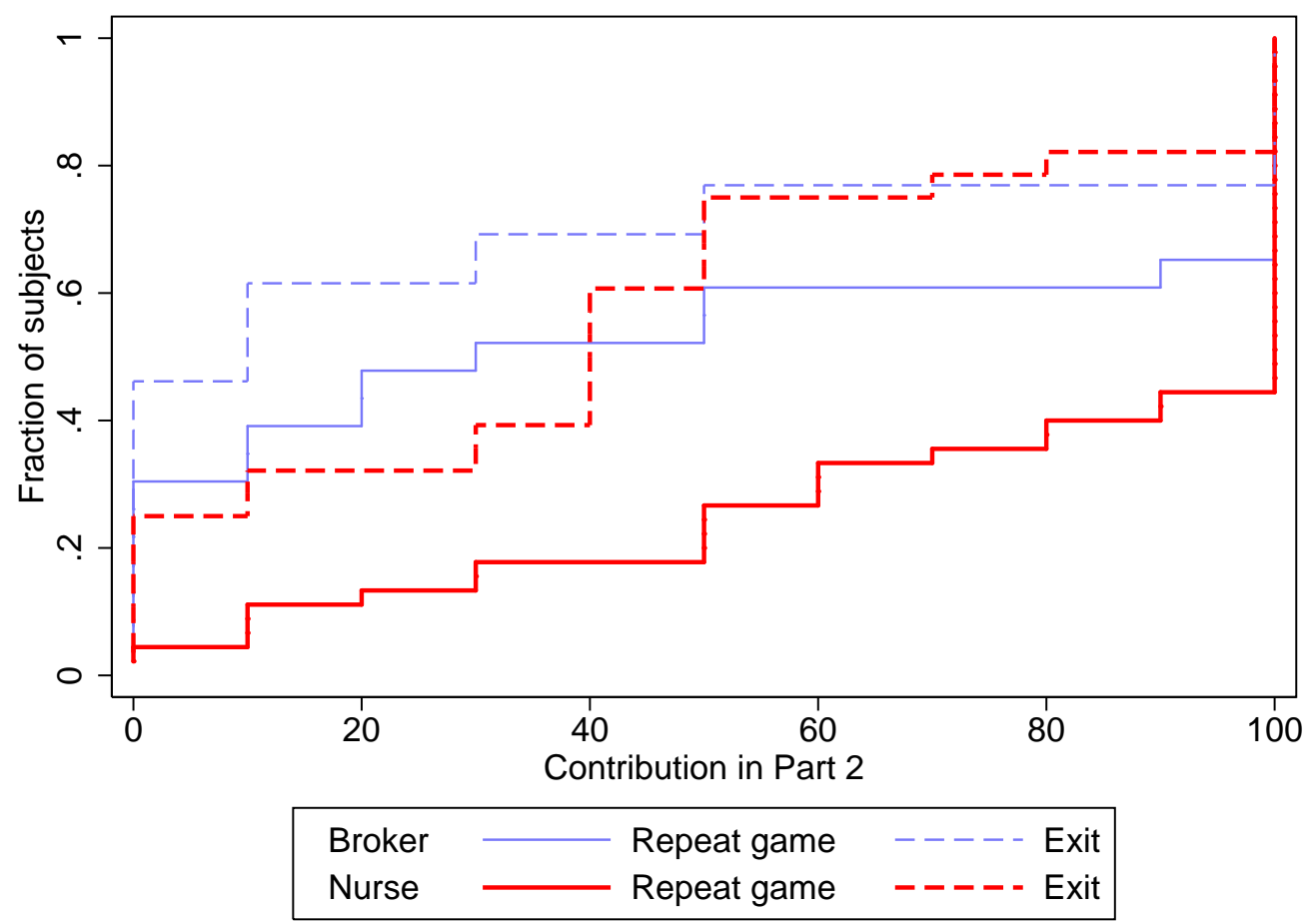

Notes: Only data from the uncertain exit treatment used. 